\title{
A Research of the Relationship between Organizational Justice and Organizational Retaliatory Behavior: Based on the Moderator of Emotionality
}

\author{
Yonghua Pi \\ Silk Road Business School \\ Hainan Silk Road Commercial Civilization Research Base \\ University of Sanya \\ Sanya, 572022, China \\ ceo_868@qq.com
}

\begin{abstract}
Organizational justice is an important predicting index for the effective functioning of organizations. There are many organizational variables affected by organizational justice, such as organizational retaliatory behavior (ORB). In this study, it performed a test for the moderating role of the personality of emotionality in the relationship between organizational justice and organizational retaliatory behavior. And it was found that emotionality weakened partly the negative relationships between organizational justice and organizational retaliatory behavior.
\end{abstract}

Keywords-organizational justice; organizational retaliatory behavior; emotionality

\section{INTRODUCTION}

As truth is the first virtue of ideology, justice has been claimed to be the first virtue of social institutions. Justice has been a research attention all the while. However, justice involves different fields: social justice focuses on the harmony of whole society while organizational justice relates to distribution and motivation in organization. And organizational justice is an important predicting index for the effective functioning of organizations [1].

\section{A. Organizational justice}

Organizational justice focuses on the perceived fairness of employees on the decision result and decision process. It was founded that organizational justice presents different factor structure from different angle of view, such as double-factor model (including distributive justice and procedural justice), three-factor model (including distributive justice, procedural justice and interactional justice) and four-factor model (including distributive justice, procedural justice, interpersonal justice and informational justice). And the dimensions of organizational justice influence each other. Why are people interested in the problem of organizational justice? Based on the content theory of motivation, some researchers explained that organizational justice can satisfy the need, for example, justice influences people's benefits while it can present their

This study was supported by the 2016 Planning fund for philosophy and social sciences of Hainan Province (project approval number: HNSK (JD) 16-31). status. Up to the present, there are four types of theories about this problem, including the self-interest model, group-value model, moral-value model and multiple-demand model. It was proved that justice influences employee's perception and behavior, and then influences enterprise performance [2]

\section{B. Organizational retaliatory behavior}

Organizational retaliatory behavior (ORB) can be defined as a subset of such negative behavior, which used to punish the organization and its representatives in response to perceived unfairness, and its frequency would increase in response to perceived injustice [3]. For the past few years, more and more researchers pay attentions to organizational retaliatory behavior [4]. ORB can be viewed as somewhat analogous to organizational citizenship behavior (OCB). Just as OCB is the thing that can be crucial to an organizations survival, ORB may detract from effective organizational functioning, while ORB may not appear to be as dangerous as an overtly aggressive act.

\section{Emotionality}

With the support of many kinds of literature, researchers put forward a personality model of five dimensions, which is called as "Big Five" model [5]. The five dimensions of personalities are named as neuroticism, extraversion, openness, agreeableness, and conscientiousness respectively. "Big Five" model was proved in the people whose languages belong to the Germanic group, such as English. However, "Big Five" model can't be applied to Chinese. It was founded that the Chinese structure of personality is different from occidental's [6]. It includes seven dimensions, which was named as Chinese "Big Seven" personalities. Based on this theory, Chinese researchers put forward some measuring scales of Chinese personality, such as QZPS and QZPAS [7][8]. In view of the differences between Chinese personalities and occidental's personalities, this study used QZPS scale to measure Chinese personalities. Especially, it used one dimension of Chinese Big Seven personalities, emotionality, as a moderator to test its effect on the relationship between organizational justice and ORB. 


\section{Hypothesis}

There are many organizational variables affected by organizational justice [9][10][11], such as ORB. However, Skarlicki et al. found that the personalities of negative affectivity and agreeableness would moderate the relationship between organizational justice and ORB [12]. As one dimension of Chinese Big Seven personalities, emotionality is defined as the stability of mood. People with high scores of emotionality can control their mood better than people with low scores. Thus, the hypothesis was put forward as follow:

Hypothesis: Emotionality will moderate the relationship between organizational justice and organizational retaliatory behavior (ORB). The relationship of high-emotionality individuals between organizational justice and ORB is different from that of low-emotionality individuals.

\section{METHODS}

Base on informed research, this study designed a fourdimension scale and two-dimension scale to measure organizational justice and ORB. In this study, ORB is divided into two types: organizational retaliatory behavior to the individual (ORBI) and organizational retaliatory behavior to organization (ORBO). First, it tested these two scales by obtaining an independent random sample of 50 employees to make them more available for subsequent research. Second, it made a formal survey for three months at Hangzhou, Ningbo, Shanghai and Jiujiang cities. Then, this study used some analytical methods to process data, such as CITC, singledimension analysis, Confirmatory factor analysis, Pearson correlation, t-test, ANOVA, etc.

At last, this study handed out questionnaires to 1340 randomly selected employees, and received responses from 1139 employees. It deleted some questionnaires according to three rules: 1 . subject hadn't a formal job; 2 . there existed one whole page not been filled in a questionnaire; 3 . there were many default values in a questionnaire. After deleting invalid questionnaires, this study obtained 1044 valid questionnaires. And the recovery rate of questionnaires was $77.9 \%$, which comes up to the analysis criterion. Meanwhile, it used QZPS scales to measure emotionality.

\section{RESULTS}

The scales' alpha reliabilities were all greater than 0.7 , which comes up to the analysis criterion.

\section{A. Confirmatory factor analyses of organizational justice and ORB}

This study used confirmatory factor analysis (CFA) to confirm the factor structure of organizational justice scale. It compared single-factor model (assuming that all the items were used to measure one factor), double-factor model (assuming that items of procedural justice, interpersonal justice and informational justice were used to measure one factor), threefactor model (assuming that items of interpersonal justice and informational justice were used to measure one factor) and four-factor model. It was shown as table I and the indexes of four-factor model match best. It was indicated that distributive justice, procedural justice, interpersonal justice and informational justice were four different dimensions.

CFA was also used to confirm the factor structure of ORB scale. It compared single-factor model (assuming that all the items are used to measure one factor), double-factor model. It was shown as table $\mathbb{I}$ and the indexes of double-factor model match better. It was indicated that ORBI and ORBO were two different dimensions.

TABLE I. CFAs OF ORGANIZATIONAL JUSTICE

\begin{tabular}{cccccccc}
\hline & $\chi^{2}$ & df & GFI & NFI & TLI & CFI & RMSEA \\
\hline single-factor model & 12696.930 & 405 & 0.333 & 0.551 & 0.526 & 0.559 & 0.171 \\
double-factor model & 5988.026 & 404 & 0.622 & 0.788 & 0.784 & 0.799 & 0.115 \\
three-factor model & 3790.776 & 402 & 0.753 & 0.866 & 0.868 & 0.878 & 0.090 \\
four-factor model & 2415.506 & 399 & 0.862 & 0.915 & 0.921 & 0.928 & 0.070 \\
\hline
\end{tabular}

TABLE II. CFAS OF ORB

\begin{tabular}{cccccccc}
\hline & $\chi^{2}$ & $\mathrm{~d} f$ & GFI & NFI & TLI & CFI & RMSEA \\
\hline single-factor model & 995.534 & 54 & 0.833 & 0.793 & 0.757 & 0.801 & 0.129 \\
double-factor model & 629.128 & 53 & 0.900 & 0.869 & 0.848 & 0.878 & 0.102
\end{tabular}

\section{B. Moderating effect of emotionality}

This study used hierarchical regression analysis to test the moderating effect of emotionality on the relationship between organizational justice and ORB. In the first step, it regressed ORBI and ORBO separately, on seven demographic and control variables. In step 2, it entered justice predictor and emotionality variable. In step 3, it entered two-way interaction between justice and emotionality. It tested the significance of the moderating effect on the relationship between organizational justice and ORB by examining the change in R2.

The results were presented in Table III. It was indicated that the interaction between procedural justice and emotionality made a new contribution to ORBI after controlling demographic and control variables and main independent variables. And the change in R2 added $0.5 \% \quad(\beta=0.391$, $\mathrm{P}<0.05)$. It was indicated that the interaction between interpersonal justice and emotionality made a new contribution to ORBI after controlling demographic and control variables and main independent variables. And the change in R2 added $0.3 \%(\beta=0.332, P<0.05)$. It was indicated that the interaction between distributive justice and emotionality made a new contribution to ORBO after controlling demographic and control variables and main independent variables. And the change in $\mathrm{R} 2$ added $0.7 \%(\beta=0.496, \mathrm{P}<0.01)$. It was indicated that the interaction between procedural justice and emotionality made new contribution to ORBO after controlling demographic and control variables and main independent variables. And the change in R2 added $2 \%(\beta=0.759, \mathrm{P}<0.001)$. It was indicated that the interaction between interpersonal justice and emotionality made new contribution to ORBO after controlling demographic and control variables and main independent variables. And the change in R2 added $0.8 \% \quad(\beta=0.505$, $\mathrm{P}<0.01)$. It was also indicated that the interaction between informational justice and emotionality made new contribution to ORBO after controlling demographic and control variables and main independent variables. And the change in R2 added $0.7 \% \quad(\beta=0.468, \mathrm{P}<0.01)$. Hence, the hypothesis was partly 
supported. It meant that emotionality would weaken partly the negative relationships between organizational justice and ORBs.

TABLE III. EMOTIONALITY IS A MODERATOR IN THE HIERARCHICAL REGRESSIONS

\begin{tabular}{|c|c|c|c|}
\hline & & ORBI & ORBO \\
\hline \multirow[t]{17}{*}{ Step1 } & AGE & -.071 & $-.147 * *$ \\
\hline & GENDER1 & $-.118 * * *$ & -.054 \\
\hline & MARRIED1 & .031 & .022 \\
\hline & E1 & .039 & .076 \\
\hline & E2 & -.018 & .088 \\
\hline & E3 & -.043 & .086 \\
\hline & $\mathrm{T} 1$ & .026 & $.076^{*}$ \\
\hline & $\mathrm{T} 2$ & .079 & $.133 * *$ \\
\hline & T3 & -.017 & .055 \\
\hline & $\mathrm{T} 4$ & -.012 & .088 \\
\hline & $\mathrm{P} 1$ & .046 & -.026 \\
\hline & $\mathrm{P} 2$ & .058 & .021 \\
\hline & O1 & -.044 & -.001 \\
\hline & $\mathrm{O} 2$ & -.056 & -.005 \\
\hline & O3 & -.065 & $-.079 *$ \\
\hline & $\mathrm{O} 4$ & -.049 & -.085 \\
\hline & $\Delta R^{2}$ & $.034 * *$ & $.035 * *$ \\
\hline \multirow[t]{12}{*}{ Step2 } & Distributive justice & $-.091^{* *}$ & $-.187 * * *$ \\
\hline & Emotionality & $.305^{* * *}$ & $.239 * * *$ \\
\hline & $\Delta R^{2}$ & $.100 * * *$ & $.093^{* * *}$ \\
\hline & Procedural justice & $-.094 * *$ & $-.235 * * *$ \\
\hline & Emotionality & $.304 * * *$ & $.233^{* * *}$ \\
\hline & $\Delta R^{2}$ & $.101^{* * *}$ & $.112^{* * *}$ \\
\hline & Interpersonal justice & $-.106^{* *}$ & $-.230 * * *$ \\
\hline & Emotionality & $.295^{* * *}$ & $.215^{* * *}$ \\
\hline & $\Delta R^{2}$ & $.103^{* * *}$ & $.108^{* * *}$ \\
\hline & Informational justice & $-.096 * *$ & $-.245 * * *$ \\
\hline & Emotionality & $.300^{* * *}$ & $.223 * * *$ \\
\hline & $\Delta R^{2}$ & $.101^{* * *}$ & $.116^{* * *}$ \\
\hline \multirow[t]{8}{*}{ Step3 } & Distributive justice $\times$ Emotionality & .167 & $.496 * *$ \\
\hline & $\Delta R^{2}$ & .001 & $.007 * *$ \\
\hline & Procedural justice $\times$ Emotionality & $.391 *$ & $.759 * * *$ \\
\hline & $\Delta R^{2}$ & $.005^{*}$ & $.020 * * *$ \\
\hline & Interpersonal justice×Emotionality & $.332 *$ & $.505^{* *}$ \\
\hline & $\Delta R^{2}$ & $.003^{*}$ & $.008 * *$ \\
\hline & Informational justice ×Emotionality & .314 & $.468 * *$ \\
\hline & $\Delta R^{2}$ & .003 & $.007 * *$ \\
\hline
\end{tabular}

The plot was constructed to illustrate the nature of the significant interaction between procedural justice and emotionality (Fig. 1). High and low level of emotionality were calculated by subtracting one standard deviation above the mean of emotionality and one standard deviation below the mean of emotionality. It was indicated that emotionality weakened the negative relationship between procedural justice and ORBI.

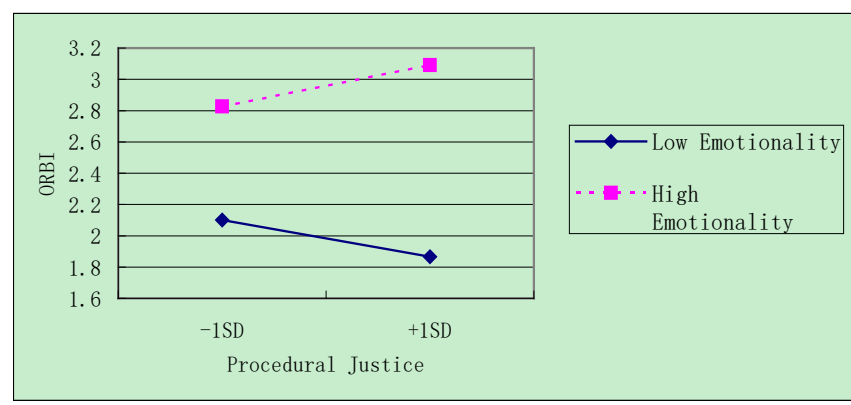

Fig. 1. The interaction effect of emotionality on procedural justice and ORBI

Similarly, Plot was constructed to illustrate the nature of the significant interaction between interpersonal justice and emotionality (Fig. 2). It was indicated that emotionality weakened the negative relationship between interpersonal justice and ORBI.

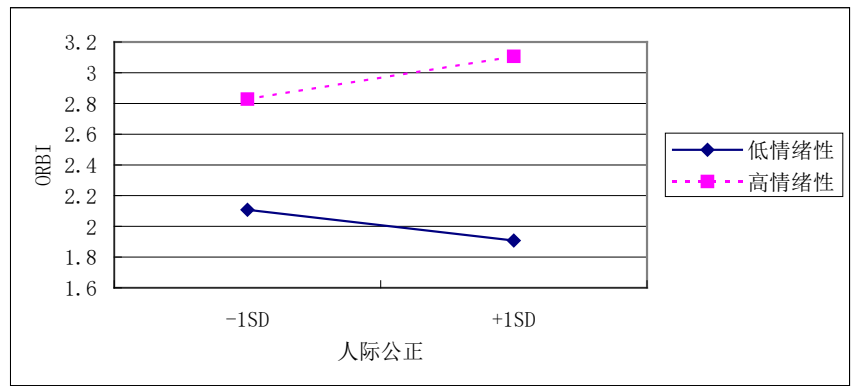

Fig. 2. The interaction effect of emotionality on interpersonal justice and ORBI

Similarly, Plot was constructed to illustrate the nature of the significant interaction between distributive justice and emotionality (Fig. 3). It was indicated that emotionality weakened the negative relationship between distributive justice and ORBO.

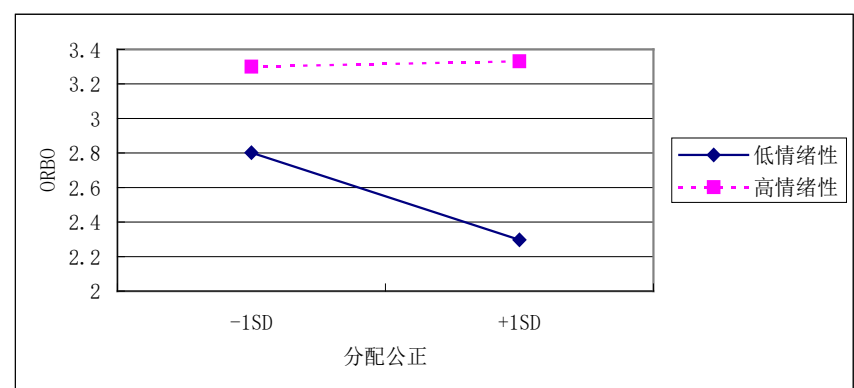

Fig. 3. The interaction effect of emotionality on distributive justice and ORBO

Similarly, Plot was constructed to illustrate the nature of the significant interaction between procedural justice and emotionality (Fig. 4). It was indicated that emotionality weakened the negative relationship between procedural justice and ORBO. 


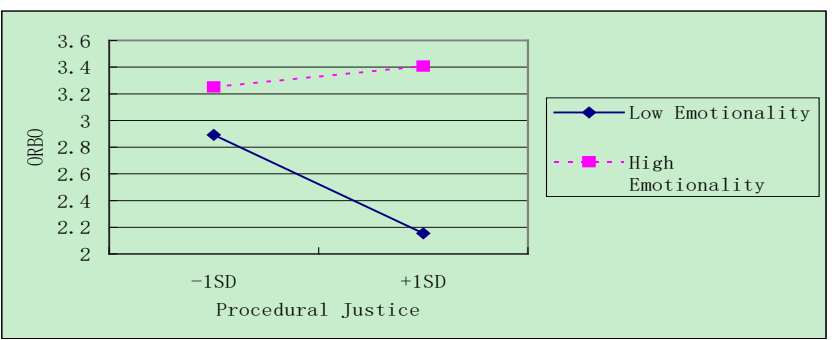

Fig. 4. The interaction effect of emotionality on procedural justice and ORBO

Similarly, Plot was constructed to illustrate the nature of the significant interaction between interpersonal justice and emotionality (Fig. 5). It was indicated that emotionality weakened the negative relationship between interpersonal justice and ORBO.

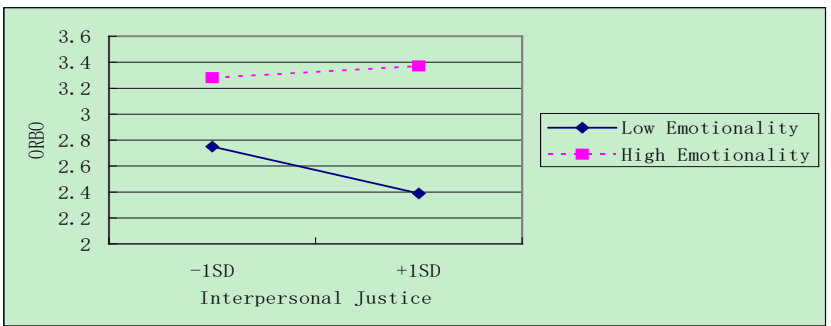

Fig. 5. The interaction effect of emotionality on interpersonal justice and ORBO

Similarly, Plot was constructed to illustrate the nature of the significant interaction between informational justice and emotionality (Fig. 6). It was also indicated that emotionality weakened the negative relationship between informational justice and ORBO.

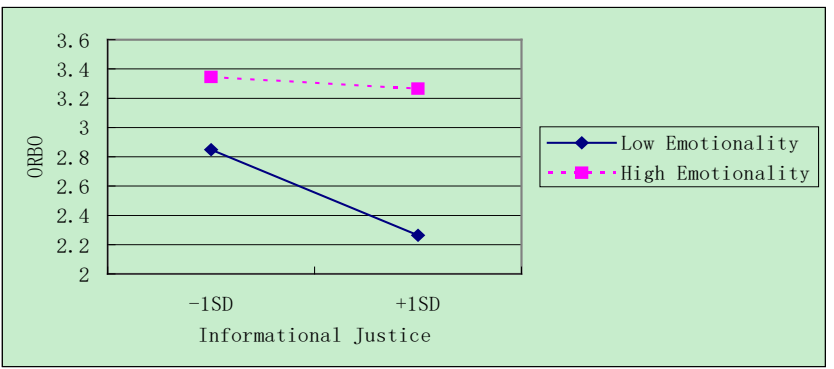

Fig. 6. The interaction effect of emotionality on informational justice and ORBO

\section{CONCLUSION}

It was found that emotionality would moderate the relationship between organizational justice and ORB. In fact, emotionality weakened the negative relationship between procedural justice/interpersonal justice and ORBI and the negative relationship between all the dimensions of organizational justice and ORBO. Given the same perceived procedural/interpersonal injustice, low-emotionality individuals are more inclined to take ORBIs than high-emotionality individuals. In the meanwhile, given the same perceived organizational injustice, low-emotionality individuals are more inclined to take ORBOs than high-emotionality individuals. As has been stated, emotionality is defined as the stability of mood. People with high scores of emotionality can control their mood better than people with low scores. Therefore, low-emotionality individuals are more easily affected by their perceived justice than high-emotionality individuals.

In the subsequent studies, some mediating variables may be considered entering into the research about the relationship between organizational justice and ORB, including trust, leader-member exchange (LMX) [13] and organizational support, etc. In the meanwhile, this study only made a test for the moderating effect of one dimension of Chinese Big Seven personalities, such as emotionality. As a new theory about Chinese structure of personality, there are many problems that have not been explained. It is important to do more tests for Chinese structure of Big Seven personalities in the future.

\section{REFERENCES}

[1] X. Zhang and Y. Wang, "How does organizational justice motivate the organization? A group-level study on the influence and its mechanisms of justice climate on group voice behavior," Foreign Economics \& Management, 2018, 40(6): pp.116-128 (In Chinese)

[2] J. Mi, "A review of organizational justice theories," Commercial Research, 2004, (6): pp.86-90

[3] D. P. Skarlicki and R. Folger, "Retaliation in the workplace: The roles of distributive, procedural, and interactional justice,” Journal of Applied Psychology, 1997, 82(3): pp.434-443

[4] S. Xu and K. Ouyang, "The impact of leader justice and information justice on organizational retaliation behavior: A perspective of referent cognitions theory,” Chinese Journal of Management, 2012, 9(10): pp.1457-1463 (In Chinese)

[5] R. R. McCrae and P. T. Costa, "Validation of the five-factor model of personality across instruments and observers," Journal of Personality and Social Psychology, 1987, 52: pp.81-90

[6] K. S. Yang and M. H. bond, "Exploring implicit personality theories with indigenous or imported constructs: The Chinese case,” Journal of Personality and Social Psychology, 1990, 58: pp.1087-1095

[7] D. Wang and H. Cui, "Processes and preliminary results in the construction of the Chinese personality scale (QZPS)," Acta Psychologica Sinica, 2003, 35(1): pp.127-136 (In Chinese)

[8] H. Cui and D. Wang, "Reliability, validation, and norm for the Chinese personality adjective rating scale (QZPAS),” Psychological Science, 2004, 27 (1): pp.31-33 (In Chinese)

[9] L. Zhang and Z. Lian, "Relationship between self-efficacy and innovation performance of the new generation staffs: a model of mediation moderated of organizational justice," Chinese Journal of Management, 2017, 14(8): pp.1162-1171 (In Chinese)

[10] C. Cheng, Y. Zhang, Y. Chen, and H. Xie, “Do entrepreneurs' political skills promote new venture performance? Testing a model of entrepreneurial orientation and organizational justice mediate moderation,” Studies in Science of Science, 2014, 32(8): pp.1198-1206 (In Chinese)

[11] J. Xie, L. Wang, X. Chu, and J. Huang, "The mediating effect of psychological empowerment: the formatting mechanism of employee creativity from an organizational justice perspective,” Chinese Journal of Management, 2013,10(2): pp.206-212 (In Chinese)

[12] D. P. Skarlicki, R. Folger, and P. Tesluk, "Personality as a moderator in the relationship between fairness and retaliation," Academy of Management Journal, 1999, 42(1): pp.100-108

[13] Y. Jin, "The relationship between organizational justice and psychological contract breach: social exchange theory perspective," Journal of Business Economics, 2014, 277(11): pp.50-56 (In Chinese) 